\title{
PREVALENCE, DISTRIBUTION AND DETERMINANTS OF DEEP VEIN THROMBOSIS IN ADULT INDOOR STROKE POPULATION OF PESHAWAR DIVISION, PAKISTAN
}

\author{
Muhammad Bilal', Imran Ullah², Syed Abdurehman Shah ${ }^{3}$, Zahidullah Khan', Taj Muhammad Khan ${ }^{4}$, \\ Ghazala Shaheen ${ }^{4}$ \\ Departments of ${ }^{1}$ Accident \& Emergency, ${ }^{2}$ Medicine \& ${ }^{3}$ Neurology, Lady Reading Hospital, Peshawar, \\ ${ }^{4}$ Department of Medicine, Pak International Medical College, Peshawar, Pakistan
}

\begin{abstract}
Background: Deep vein thrombosis (DVT) in stroke is a major cause of morbidity and mortality. Our objectives were to determine the prevalence, distribution and determinants of DVT in adult indoor stroke population of Peshawar Division, Pakistan.

Materials \& Methods: This cross-sectional study was done in Department of Neurology, Lady Reading Hospital, Peshawar, Pakistan from $1^{\text {st }}$ January 2017 to 31 December 2017. 196 stroke subjects were selected from population at risk consecutively. Sex, age groups and presence of DVT were three nominal variables. Prevalence and distribution were described by count, percentage and confidence intervals for proportion for population. Hypotheses for distribution were tested by chi-square goodness of fit and of association by chi-square test of association.

Results: In 196 stroke patients, 82 (41.84\%) were men, 114 (58.16\%) women, 127 (64.80\%) in age group 20- 60 years and 69 (35.20) in age group >60 years. The prevalence of DVT was 16/196 (8.16\%, 95\%Cl 7.56-8.64). Out of 16 DVT patients, seven (3.57\%) were men and nine (4.59\%) women, $10(5.1 \%)$ in age group 20-60 and six $(3.06 \%)$ in $>60$ years. Our prevalence of DVT was similar to expected $(p=0.7071)$. Our distribution across sex $(p=0.5089)$ and age groups $(p=0.6004)$ were similar to expected. Presence of DVT was not associated to sex $(p=0.8713)$ and age groups $(p=0.8409)$.

Conclusion: Prevalence of DVT in adult stroke population of Peshawar Division, Pakistan was more in women than men and more in younger age group than older age group population. Overall prevalence DVT was similar to expected. Observed distribution across sex and age groups were similar to expected. Presence DVT was not associated to sex and age groups respectively.
\end{abstract}

KEY WORDS: Deep Vein Thrombosis; Stroke; Prevalence; Distribution; Adult; Sex; Age Groups; Chi-square Goodness of fit Test; Chi-square Test of Association; Peshawar.

Cite as: Bilal M, Ullah I, Shah SA, Khan Z, Khan TJ, Shaheen G. Prevalence, distribution and determinants of deep vein thrombosis in adult indoor stroke population of Peshawar Division, Pakistan. Gomal J Med Sci 2020 Apr-Jun; 18 (2):59-67. http://doi.org/10.46903/gjms/18.02.851

\section{INTRODUCTION}

1.1 Background: Stroke is the second common cause of mortality after cardiac diseases leading to $11.8 \%$ global mortality. ${ }^{1}$ Globally in 2013 , there were

\section{Corresponding Author:}

Dr. Syed Abdurehman Shah

Department of Neurology, Lady Reading Hospital, Peshawar, Pakistan

E-mail: sareh19@hot.com

Date Submitted: $\quad$ 17-06-2019

Date Revised: $\quad 10-01-2020$

Date Accepted: $\quad$ 01-03-2020 about 25.7 million prevalent strokes, 6.5 million mortality from stroke and 10.3 million incident strokes. From 1990 to 2013 incidence, morbidity and mortality due to stroke were significantly increased. ${ }^{2}$

In the WHO Eastern Mediterranean region, during the previous decade, stroke related mortality increased by $23 \%$, from 250,558 mortality in 2000 to 308,050 mortality in $2011 .{ }^{3}$ In USA, stroke is the third common cause of mortality, despite decreasing number of new cases in the previous three decades. The exact explanation for this decrease is unknown, but increased knowledge of determinants and better preventive activities and screening of those 
at greater risk could be the reason. ${ }^{4}$ China conducted population survey in 31 provinces in 2013 on 480,687 adults $\geq 20$ years showing 7,672 prevalent $(7,672 * 100 / 480,687=1.6 \%)$ and 1,643 incident strokes $(1,643 * 100 / 480,687=0.34 \%)$ respectively. ${ }^{5}$

Kelly, et al. ${ }^{6}$ showed that DVT and pulmonary embolism cause significant morbidity and mortality, with pulmonary embolism causing up to $25 \%$ of early deaths after stroke. A study from Troms $\varnothing$, a city of Norway with 30,002 participants conducted in 19941995, 2001, and 2007-2008 and followed through 2010, showed that the risk of DVT and thromboembolism is increased in the first one to three months after stroke, due to stroke related immobility. ${ }^{7}$

Bembenek, et al. ${ }^{8}$ from Warsaw city of Poland conducted a study from December 2007 to May 2009 with 323 acute stroke patients, including157 (48.60\%) men and 166 (51.40\%) women. He showed the frequency of DVT as $28 / 323(8.67 \%)$, of which eight $(2.48 \%)$ were men and $20(6.19 \%)$ women $(p<.05)$.

Abdel-Aziz, et al. ${ }^{9}$ from Zagazig, a city in Egypt for the period from January 2012 to June 2012 included 280 indoor stroke patients, with $130(46.43 \%)$ men and150 (53.57\%) women and $210(75 \%)$ in age group $\leq 65$ years and $70(25 \%)$ in age group $>65$ years respectively. He showed frequency of DVT as $25 / 280(8.93 \%)$. Of $8.93 \%$ DVT patients, $13 / 280$ $(4.64 \%)$ were men and $12 / 280(4.29 \%)$ women $(p=.558)$, and $14 / 280(5 \%)$ were in age group $\leq 65$ years and $11 / 280(3.93 \%)$ in age group $>65$ years respectively $(\mathrm{p}=.022)$.

The CLOTS trials ${ }^{10} 1$ and 2 together screened 5,632 immobile stroke patients with compression duplex ultrasound (CDU) in 135 hospitals in nine countries. The frequency of DVT was $817(817 * 100 / 5632=14.50 \%)$, including 641 (11.40\%) on first CDU at a median of 8 days and an additional 176 (3.10\%) on subsequent CDU at a median of 28 days. These included 528 $(528 * 100 / 5,632=9.37 \%)$ asymptomatic and 289 symptomatic $(289 * 100 / 5632=5.13 \%)$ cases.

Tso SC. ${ }^{11}$ from China showed seven cases of DVT in $35(17 \%)$ stroke patients, using 125l-fibrinogen scan. Karman, et al. ${ }^{12}$ showed 23 cases of DVT in 249 (9.24\%) non-hemorrhagic stroke patients from October 1988 through February 1993. Kelly, et al. ${ }^{13}$ showed $18 \%$ prevalence of proximal deep vein thrombosis (PDVT) in 102 patients of acute ischemic stroke 21 days after stroke.

1.2 Research Problems (RPs), Knowledge Gaps (KGs), Research Questions (RQs) \& Rationale: Unawareness about the prevalence, distribution (across sex and age groups) and determinants (association to sex and age groups) of DVT in adult indoor stroke population of Peshawar Division, Pakistan are our five RPs. Unavailability of data regarding these RPs are our five knowledge gaps and rationale for our study. What will be the prevalence, distribu- tion and determinants of DVT in adult indoor stroke population of Peshawar Division, Pakistan are our five research questions.

\subsection{Research Objectives (ROs)}

RO-1: To find the prevalence of DVT in adult indoor stroke population of Peshawar Division, Pakistan.

RO 2-3: To find the distribution of DVT across the sex and age groups respectively in adult indoor stroke population of Peshawar Division, Pakistan.

RO 4-5: To find the association between DVT and sex and age groups respectively in adult indoor stroke population of Peshawar Division, Pakistan.

\subsection{Research (Null) Hypotheses}

$\mathbf{H}_{01}$ : The observed prevalence of DVT is similar to expected in adult indoor stroke population of Peshawar Division, Pakistan.

$\mathbf{H}_{02}$ : The observed distribution of DVT across the sex is similar to expected in adult indoor stroke population of Peshawar Division, Pakistan.

$\mathbf{H}_{03}$ : The observed distribution of DVT across the age groups is similar to expected in adult indoor stroke population of Peshawar Division, Pakistan.

$\mathbf{H}_{04}$ : Presence of DVT and sex were not associated with each other in adult indoor stroke population of Peshawar Division, Pakistan.

$\mathbf{H}_{05}$ : Presence of DVT and age groups were not associated with each other in adult indoor stroke population of Peshawar Division, Pakistan.

1.5 Significance: This study will determine the magnitude of the problem i.e. overall prevalence, and distribution of DVT in stroke population across sex and age groups. Further this study may identify determinants of DVT in terms of association to sex and age groups. It will help the public health specialists and clinicians to plan strategic interventions. Further it will provide base line data for further research into the cause-n-effect investigation as case-control and cohort studies.

\subsection{Operational Definitions:}

Stroke: Stroke was defined as sudden occurrence of a neurologic deficit of focal vascular origin remaining for $>24$ hours. ${ }^{14}$

Deep Vein Thrombosis: DVT was defined as patients having non compressible segment of the vein and/ or flow impairment within vein identified on Complex Doppler Ultrasound.

\section{MATERIALS AND METHODS}

2.1 Study Design, Settings \& Duration: This cross-sectional study was carried on in Department of Neurology, Lady Reading Hospital, Peshawar, Pakistan from 01 Jan 2017 to 31 Dec 2017. The data was collected from Neurology ward, Lady Reading Hospital, Peshawar.

2.2 Population, Sample Size \& Technique and 
Sample Selection: Peshawar Division (consisting of districts Peshawar, Nowshera, Charsadda) is the populous division of Khyber Pukhtunkhwa; a province in the north-west of Pakistan. Its population was $3,923,588$ in 1998 Census. For 2016, it was estimated to be around 7,220,647. Age group $>19$ years was assumed to contribute its $48 \%$, hence $3,465,911$ population. With overall presumed prevalence rate of $1.6 \%$ of stroke in this age group, ${ }^{5}$ the population with stroke (population at risk) will be around 55,455 $(1.6 * 3,465,911 / 100=55,455)$. With this much population, expected prevalence rate of $8.93 \%{ }^{9} \mathrm{DVT}$ in this population, margin of error $3.99 \%$ and confidence interval of 95\%, sample size was calculated as 196 using online calculator Raosoft ${ }_{\circledast}{ }^{15}$

Consecutive non-probability sampling technique was used. Adult (>19 years) indoor patients with new stroke were eligible for inclusion. The patients with history of previous stroke/ DVT, peripheral vascular disease, thrombotic hematological disorders, active severe infections, malignancy, kidney or hepatic disease, chronic lung disease and inflammatory bowel disease were excluded from the study.

2.3 Conduct of Procedure: Prior approval of the project was sought from the Hospital Ethical Review Committee. Consent of patients/ attendants was sought before inclusion in the study. All patients were subjected to detailed history, examination and routine investigations, including CT brain. All these patients were subjected to complex Doppler ultrasound to confirm diagnosis of DVT.

2.4 Data Collection Plan: Grouping / independent variables were sex (men/ women) and age groups (20-60 years and $>60$ years) while research/ dependent variable was presence of DVT (yes and no). The data type was nominal for all the variables.

\subsection{Data Analysis Plan}

2.5.1 Descriptive Statistics and Estimation of $\mathrm{Pa}$ rameters: The three variables for the sample were analyzed by count and percentage. The estimated parameters of these three variables for the population were analyzed as C.I (confidence interval) for proportion at $95 \%$ C.L (confidence level) using the Wilson score interval for binomial distribution using online statistical calculator. ${ }^{16}$

2.5.2 Hypotheses Testing: Observed and expected prevalence and observed and expected distribution of DVT across sex and age groups were calculated by using chi-square goodness of fit test $\left(\mathrm{H}_{01-3}\right) .{ }^{17-19}$ The association between the presences of DVT and sex and age groups was calculated by using chi-square test of association/ independence $\left(\mathrm{H}_{04-5}\right) \cdot{ }^{17,18,20}$

\section{RESULTS}

\subsection{Descriptive Statistics \& Estimation of Param- eters}

3.1.1 Sample Description \& Prevalence of DVT in adult stroke population: Out of 196 patients with stroke, $82(41.84 \%)$ were men and $114(58.16 \%)$ women, 127 (64.80\%) were in age group 20-60 years and $69(35.20 \%)$ in age group of $>60$ years.

Out of 196 patients with stroke, $16(8.16 \%)$ had DVT, while $180(91.84 \%)$ had no DVT. Estimated prevalence in population is shown below. (Table 3.1.1)

3.1.2 Distribution of positive cases of DVT in adult indoor stroke population across the sex and age groups: The distribution of positive cases of DVT across sex and age groups in adult indoor stroke population of Peshawar Division is shown in Table 3.1.2. Here the frequency of DVT in sample and its estimated prevalence in population was higher in women 4.59 $\%$ than men $3.57 \%$ and higher in age group $20-60$ years $5.10 \%$ than age group $>60$ years $3.06 \%$.

Table 3.1.1: Prevalence of DVT in adult indoor stroke population of Peshawar Division, Pakistan $(n=196)$

\begin{tabular}{|l|l|c|c|c|c|}
\hline \multirow{2}{*}{ Variable } & \multirow{2}{*}{ Attributes } & \multicolumn{2}{|c|}{ Sample statistics } & \multicolumn{2}{c|}{$95 \% \mathrm{Cl}$ for proportion for population } \\
\cline { 3 - 6 } & & Count & Percentage & Lower & Upper \\
\hline \multirow{3}{*}{$\begin{array}{l}\text { Presence of } \\
\text { DVT }\end{array}$} & Yes & 16 & $8.16 \%$ & 7.56 & 8.64 \\
\cline { 2 - 6 } & No & 180 & $91.84 \%$ & 87.16 & 94.92 \\
\cline { 2 - 6 } & Total & 196 & 100 & \multicolumn{2}{|c}{ Population parameters } \\
\hline
\end{tabular}

Table 3.1.2: Distribution of positive cases of DVT across the sex and age groups in adult indoor stroke population of Peshawar Division, Pakistan $(n=16 / 196)$

\begin{tabular}{|l|l|c|c|c|c|c|}
\hline \multirow{2}{*}{ Variables } & \multirow{2}{*}{ Attributes } & \multirow{2}{*}{$\begin{array}{c}\text { Sample } \\
\text { size }\end{array}$} & \multicolumn{3}{|c|}{ Sample statistics } & \multicolumn{2}{c|}{$95 \% \mathrm{Cl}$ for proportion } \\
\cline { 5 - 7 } & & Count & Percentage & Lower & Upper \\
\hline \multirow{2}{*}{ Sex } & Men & 82 & 7 & $7^{*} 100 / 196=3.57 \%$ & 2.93 & 4.26 \\
\cline { 2 - 7 } & Women & 114 & 9 & $9^{*} 100 / 196=4.59 \%$ & 3.91 & 5.29 \\
\hline \multirow{2}{*}{ Age groups } & $20-60$ years & 127 & 10 & $10^{*} 100 / 196=5.10 \%$ & 4.40 & 5.79 \\
\cline { 2 - 7 } & $>60$ years & 69 & 6 & $6^{*} 100 / 196=3.06 \%$ & 2.46 & 3.74 \\
\hline & Total & 196 & 16 & $16^{*} 100 / 196=8.16 \%$ & 7.56 & 8.64 \\
\hline
\end{tabular}




\subsection{Hypotheses Testing:}

\subsubsection{Observed vs. expected prevalence of DVT} in adult indoor stroke population $\left(\mathrm{H}_{01}\right)$ :

Our observed counts for the presence of DVT(yes: no) were 16:180 from a sample of 196 against expected counts of 25:255 from a sample of 280 as reported by Abdel-Aziz, et al. ${ }^{9}$ With different sample sizes/ denominators, comparison was not possible. Hence the expected counts and expected percentages were adjusted for a sample of 196 . The expected counts of 25:255 were replaced by $17.5: 178.5$. Adjusted expected percentages came similar to expected percentages, so not changed. (Table 3.2.1.1)

Chi-square goodness of fit test showed $p$-value greater than alpha. $\mathrm{H}_{01}$ was declared as true and therefore accepted; showing that the observed prevalence is similar to the expected prevalence. Simply, the prevalence of $8.16 \%$ of DVT in our population is similar to what we were expecting from the adjusted expected counts and adjusted expected percentage of $8.93 \%$ from Abdel-Aziz, et al. ${ }^{9}$ (Table 3.2.1.2)
3.2.2 Observed vs. expected distribution of positive cases of DVT across the sex in adult indoor stroke population $\left(\mathrm{H}_{02}\right)$ :

Our observed distribution for men versus women was 7:9 out of 16 positive cases from a sample of 196 adult indoor stroke patients against expected counts of $13: 12$ out of 25 positive cases of DVT in 280 adult stroke population as reported by Abdel- Aziz, et al. ${ }^{9}$ from Zagazig, Egypt for the period from January 2012 to June $2012\left(25^{*} 100 / 280=8.93 \%\right)$. With different sample sizes/ denominators, comparison was not possible. Hence the expected counts and expected percentages were adjusted for a sample of 196. The expected counts of 13:12 were replaced by 8.32:7.68 and expected percentages of $4.64 \%: 4.29 \%$ were replaced by $4.24 \%: 3.92 \%$. Remember that we are distributing only 16 positives $(8.16 \%)$ and not the $180(91.84 \%)$ negative cases out of 196 (100\%) cases. (Table3.2.2.1)

Chi-square goodness of fit test showed p-value >alpha. $\mathrm{H}_{02}$ was declared as true and therefore

Table 3.2.1.1: Observed, expected and adjusted expected counts and percentages for prevalence of DVT in adult indoor stroke population of Peshawar Division, Pakistan $(n=196)$

\begin{tabular}{|l|c|c|c|c|c|c|}
\hline $\begin{array}{l}\text { Presence of } \\
\text { DVT }\end{array}$ & $\begin{array}{c}\text { Observed } \\
\text { counts }\end{array}$ & $\begin{array}{c}\text { Observed } \\
\text { \%ages }\end{array}$ & $\begin{array}{c}\text { Expected } \\
\text { counts }\end{array}$ & $\begin{array}{c}\text { Expected } \\
\text { \%ages }\end{array}$ & $\begin{array}{c}\text { Adjusted expected } \\
\text { counts }\end{array}$ & $\begin{array}{c}\text { Adjusted expected } \\
\text { \%ages }\end{array}$ \\
\hline Yes & 16 & $8.16 \%$ & 25 & $8.93 \%$ & $25^{*} 196 / 280=17.5$ & $17.5 * 100 / 196=8.93 \%$ \\
\hline No & 180 & $91.84 \%$ & 255 & $91.07 \%$ & $255^{\star} 196 / 280=178.5$ & $178.5 * 100 / 196=91.07 \%$ \\
\hline Total & 196 & $100 \%$ & 280 & $100 \%$ & 196.0 & $100.00 \%$ \\
\hline
\end{tabular}

Table 3.2.1.2: Observed vs. expected prevalence of DVT in adult indoor stroke population of Peshawar Division, Pakistan $(n=196)$

\begin{tabular}{|l|l|c|c|c|c|c|c|c|c|}
\hline Variable & Attributes & $\mathrm{O}$ & $\mathrm{E}$ & $\mathrm{O}-\mathrm{E}$ & $(\mathrm{O}-\mathrm{E})^{2}$ & $(\mathrm{O}-\mathrm{E})^{2} / \mathrm{E}$ & $\mathrm{X}^{2}$ & d.f. & $\mathrm{p}$-value \\
\hline \multirow{3}{*}{$\begin{array}{l}\text { Presence of } \\
\text { DVT }\end{array}$} & Yes & 16 & 17.5 & -1.50 & 2.25 & 0.13 & 0.141 & 1 & 0.7071 \\
\cline { 2 - 9 } & No & 180 & 178.5 & 1.50 & 2.25 & 0.01 & $\mathrm{H}_{01}$ accepted at alpha .05 \\
\cline { 2 - 9 } & Total & 196 & 196.0 & \multicolumn{7}{|c|}{ Chi-square goodness of fit with Yates correction } \\
\hline
\end{tabular}

$\mathrm{O}=$ Observed count, $\mathrm{E}=$ Expected count, $\mathrm{X}^{2}=$ chi-square statistic, d.f. $=$ degree of freedom

Table 3.2.2.1: Observed, expected and adjusted expected counts and percentages for distribution of positive cases of DVT across sex in adult indoor stroke population of Peshawar Division, Pakistan $(n=196)$

\begin{tabular}{|c|c|c|c|c|c|c|}
\hline Presence of DVT & $\begin{array}{l}\text { Observed } \\
\text { counts }\end{array}$ & $\begin{array}{c}\text { Observed } \\
\text { \%ages }\end{array}$ & $\begin{array}{l}\text { Expected } \\
\text { counts }\end{array}$ & $\begin{array}{c}\text { Expected } \\
\text { \%ages }\end{array}$ & $\begin{array}{l}\text { Adjusted ex- } \\
\text { pected counts }\end{array}$ & $\begin{array}{l}\text { Adjusted ex- } \\
\text { pected \% }\end{array}$ \\
\hline $\begin{array}{l}\text { Positive cases in } \\
\text { men }\end{array}$ & 7 & $\begin{array}{c}7 * 100 / 196 \\
=3.57 \%\end{array}$ & 13 & $\begin{array}{c}13 * 100 / 280 \\
=4.64 \%\end{array}$ & $\begin{array}{c}13 * 16 / 25 \\
=8.32\end{array}$ & $\begin{array}{c}8.32 * 100 / 196 \\
=4.24 \%\end{array}$ \\
\hline $\begin{array}{l}\text { Positive cases in } \\
\text { women }\end{array}$ & 9 & $\begin{array}{c}9 * 100 / 196 \\
=4.59 \%\end{array}$ & 12 & $\begin{array}{c}12 * 100 / 280 \\
=4.29 \%\end{array}$ & $\begin{array}{c}12 * 16 / 25 \\
=.7 .68\end{array}$ & $\begin{array}{c}7.68 * 100 / 196 \\
=3.92 \%\end{array}$ \\
\hline Total positive & 16 & $\begin{array}{c}16 * 100 / 196 \\
=8.16 \%\end{array}$ & 25 & $\begin{array}{c}25 * 100 / 280 \\
=8.93 \%\end{array}$ & $\begin{array}{c}25 * 16 / 25 \\
=16.00\end{array}$ & $\begin{array}{c}16.00 * 100 / 196 \\
=8.16 \mathrm{~s} \%\end{array}$ \\
\hline
\end{tabular}


accepted, showing that the observations match the expected values of the population. In simple words, our observed prevalence of DVT in men $3.57 \%$ $(7 * 100 / 196=3.57 \%)$ was statistically similar to what we expected (adjusted expected) for men $4.24 \%$ $(8.32 * 100 / 196=4.24 \%) \&$ our observed prevalence of DVT in women $4.59 \%(9 * 100 / 196=4.59 \%)$ was also similar to what we expected (adjusted expected) for women $3.92 \%(6.68 * 100 / 196=3.92 \%)$ from AbdelAziz, et al. ${ }^{9}$ (Table 3.2.2.2)

3.2.3 Observed vs. expected distribution of positive cases of DVT across age groups in adult indoor stroke population $\left(\mathrm{H}_{03}\right)$ :

Our observed distribution for age group 20-60 years versus $>60$ years was $10: 6$ out of 16 positive cases from a sample of 196 against expected counts of $14: 11$ in age group of $\leq 65$ years versus $>65$ years out of 25 positive cases of DVT in 280 adult stroke population as reported by Abdel- Aziz, et al. ${ }^{9}$ $\left(25^{\star} 100 / 280=8.93 \%\right)$. With different sample sizes/ denominators, comparison was not possible. Hence the expected counts and expected percentages were adjusted for a sample of 196 . The expected counts of 14:11 were replaced by 8.96:7.04 and expected percentages of $5 \%: 3.93 \%$ were replaced by $4.57 \%: 3.59 \%$ (Table 3.2.3.1). Remember that we are distributing only 16 positives (8.16\%) and not the $180(91.84 \%)$ negative cases out of 196 (100\%) cases.

Chi-square goodness of fit test showed $p$-value $>$ alpha. $\mathrm{H}_{02}$ was declared to be true and therefore accepted, showing that the observations match the expected values of the population. It simply means that our observed prevalence of DVT in age group $>19-60$ years $5.10 \%$ was statistically similar to what we were expecting for age group $\leq 65$ years $4.57 \%$ \& our observed prevalence of DVT in age group $>60$ years $3.06 \%$ was also similar to what we were expecting for age group $>65$ years $3.59 \%$ (adjusted expected). (Table 3.2.3.2)

3.2.4 Association of presence of DVT to sex in adult indoor stroke population $\left(\mathrm{H}_{04}\right)$ :

Presence of DVT (dependent variable) to sex (independent variable) in adult stroke population was

Table 3.2.2.2: Observed vs. expected distribution of positive cases of DVT across sex in adult indoor stroke population of Peshawar Division, Pakistan $(n=16 / 196)$

\begin{tabular}{|l|l|c|c|c|c|c|c|c|c|}
\hline Variable & Attributes & $\mathrm{O}$ & $\mathrm{E}$ & $\mathrm{O}-\mathrm{E}$ & $(\mathrm{O}-\mathrm{E})^{2}$ & $(\mathrm{O}-\mathrm{E})^{2} / \mathrm{E}$ & $\mathrm{X}^{2}$ & d.f. & $\mathrm{p}$-value \\
\hline \multirow{3}{*}{ Sex } & Men & 7 & 8.32 & -1.32 & 1.74 & 0.21 & 0.436 & 1 & .5089 \\
\cline { 2 - 9 } & Women & 9 & 7.68 & 1.32 & 1.74 & 0.23 & $\mathrm{H}_{02}$ accepted at alpha .05 \\
\hline \multicolumn{2}{|c|}{ Total } & 16 & 16.00 & \multicolumn{7}{|c|}{ Chi-square goodness of fit test with Yates correction } \\
\hline
\end{tabular}

$\mathrm{O}=$ Observed count, $\mathrm{E}=$ Expected count, $\mathrm{X}^{2}=$ chi-square statistic, d.f. $=$ degree of freedom

Table 3.2.3.1: Observed, expected and adjusted expected counts and percentages for distribution of positive cases of DVT across the age groups in adult indoor stroke population of Peshawar Division, Pakistan $(n=16 / 196)$

\begin{tabular}{|l|c|c|c|c|c|c|}
\hline Presence of DVT & $\begin{array}{c}\text { Observed } \\
\text { counts }\end{array}$ & $\begin{array}{c}\text { Observed } \\
\text { \%ages }\end{array}$ & $\begin{array}{c}\text { Expected } \\
\text { counts }\end{array}$ & $\begin{array}{c}\text { Expected } \\
\% \text { ages }\end{array}$ & $\begin{array}{c}\text { Adjusted ex- } \\
\text { pected counts }\end{array}$ & $\begin{array}{c}\text { Adjusted ex- } \\
\text { pected \% }\end{array}$ \\
\hline $\begin{array}{l}\text { Positive cases in age } \\
\text { group 20-60 years }\end{array}$ & 10 & $\begin{array}{c}10^{*} 100 / 196 \\
=5.10 \%\end{array}$ & 14 & $\begin{array}{c}14^{*} 100 / 280 \\
=5 \%\end{array}$ & $\begin{array}{c}14^{*} 16 / 25 \\
=8.96\end{array}$ & $\begin{array}{c}8.96 * 100 / 196 \\
=4.57 \%\end{array}$ \\
\hline Positive cases in age & 6 & $\begin{array}{c}6 * 100 / 196 \\
=3.06 \%\end{array}$ & 11 & $\begin{array}{c}11^{*} 100 / 280 \\
=3.93 \%\end{array}$ & $\begin{array}{c}11^{*} 16 / 25 \\
=.7 .04\end{array}$ & $\begin{array}{c}7.04 * 100 / 196 \\
=3.59 \%\end{array}$ \\
\hline group >60 years & 16 & $\begin{array}{c}16 * 100 / 196 \\
=8.16 \%\end{array}$ & 25 & $\begin{array}{c}25^{*} 100 / 280 \\
=8.93 \%\end{array}$ & $\begin{array}{c}25^{*} 16 / 25 \\
=16.00\end{array}$ & $\begin{array}{c}16.00 * 100 / 196 \\
=8.16 \%\end{array}$ \\
\hline
\end{tabular}

Table 3.2.3.2: Observed vs. expected distribution of positive cases of DVT by age groups in adult indoor stroke population of Peshawar Division, Pakistan $(n=16 / 196)$

\begin{tabular}{|l|c|c|c|c|c|c|c|c|c|}
\hline Variable & Attributes & $\mathrm{O}$ & $\mathrm{E}$ & $\mathrm{O}-\mathrm{E}$ & $(\mathrm{O}-\mathrm{E}) 2$ & $(\mathrm{O}-\mathrm{E}) 2 / \mathrm{E}$ & $\mathrm{X} 2$ & d.f. & $\mathrm{p}$-value \\
\hline \multirow{2}{*}{$\begin{array}{l}\text { Age } \\
\text { groups }\end{array}$} & $20-60$ years & 10 & 8.96 & 1.04 & 1.08 & 0.12 & 0.274 & 1 & 0.6004 \\
\cline { 2 - 9 } & $>60$ years & 6 & 7.04 & -1.04 & 1.08 & 0.15 & $\mathrm{H}_{03}$ accepted at alpha .05 \\
\hline \multicolumn{3}{|c|}{ Total } & 16 & 16.00 & \multicolumn{6}{c|}{ Chi-square goodness of fit test with Yates correction } \\
\hline
\end{tabular}

$\mathrm{O}=$ Observed count, $\mathrm{E}=$ Expected count, $\mathrm{X}^{2}=$ chi-square statistic, d.f. $=$ degree of freedom 
Table 3.2.4: Association of presence of DVT to sex in adult indoor stroke population of Peshawar Division, Pakistan $(n=196)$

\begin{tabular}{|c|c|c|c|c|c|c|}
\hline \multirow{2}{*}{ Variable/ Attributes } & \multicolumn{2}{|c|}{ Presence of DVT } & \multirow{2}{*}{$\begin{array}{l}\text { Rows } \\
\text { Total }\end{array}$} & \multirow{2}{*}{$x^{2}$} & \multirow{2}{*}{ d.f. } & \multirow{2}{*}{ p-value } \\
\hline & Yes & No & & & & \\
\hline Sex & $\mathrm{O} \quad(\mathrm{E}) \quad\left[\mathrm{X}^{2}\right]$ & $\mathrm{O} \quad(\mathrm{E})$ & \multicolumn{4}{|c|}{$\mathrm{X}^{2}$ test of association with Yates correction } \\
\hline Men & $7(6.69)[0.01]$ & 75 (75.31) $[0.00]$ & 82 & \multirow{2}{*}{0.0262} & \multirow{2}{*}{1} & \multirow{2}{*}{0.8713} \\
\hline Women & $9(9.31)$ [0.01] & 105 (104.69) [0.00] & 114 & & & \\
\hline Columns Total & 16 & 180 & 196 & \multicolumn{3}{|c|}{$\mathrm{H}_{04}$ accepted at alpha 0.05} \\
\hline
\end{tabular}

$\mathrm{O}=$ Observed count, $\mathrm{E}=$ Expected counts, $\mathrm{X}^{2}=$ chi-square statistic, d.f. = degree of freedom

Table 3.2.5: Association of presence of DVT to age groups in adult indoor stroke population of Peshawar Division, Pakistan $(n=196)$

\begin{tabular}{|c|c|c|c|c|c|c|}
\hline \multirow{2}{*}{ Variable/ Attributes } & \multicolumn{2}{|c|}{ Presence of DVT } & \multirow{2}{*}{$\begin{array}{c}\text { Rows } \\
\text { Total }\end{array}$} & \multirow{2}{*}{$x^{2}$} & \multirow{2}{*}{ d.f. } & \multirow{2}{*}{$\mathrm{p}$-value } \\
\hline & Yes & No & & & & \\
\hline Age groups & $\mathrm{O} \quad(\mathrm{E}) \quad\left[\mathrm{X}^{2}\right]$ & $\mathrm{O} \quad(\mathrm{E})$ & \multicolumn{4}{|c|}{$X^{2}$ test of association with Yates correction } \\
\hline 20-60years & $10(10.37)[0.01]$ & $117(116.63)[0.00]$ & 127 & \multirow{2}{*}{0.0403} & \multirow{2}{*}{1} & \multirow{2}{*}{0.8409} \\
\hline$>60$ years & $6(5.63)[0.02]$ & $63 \quad(63.37)[0.00]$ & 69 & & & \\
\hline Columns Total & 16 & 180 & 196 & \multicolumn{3}{|c|}{$\mathrm{H}_{05}$ accepted at alpha 0.05} \\
\hline
\end{tabular}

$\mathrm{O}=$ Observed count, $\mathrm{E}=$ Expected count, $\mathrm{X}^{2}=$ chi-square statistic, d.f. $=$ degree of freedom

substantiated. Having p-value more than alpha, $\mathrm{H}_{04}$ was declared as true and therefore accepted, revealing that the presence of DVT is independent of sex i.e. presence of DVT and sex is not associated to each other. (Table 3.2.4)

3.2.5 Association of presence of DVT to age groups in adult indoor stroke population $\left(\mathrm{H}_{05}\right)$ :

Presence of DVT (dependent variable) to age groups (independent variable) in adult stroke population was substantiated. Having p-value more than alpha, $\mathrm{H}_{04}$ was declared as true and therefore accepted, revealing that the presence of DVT is independent of age groups i.e. presence of DVT and age groups is not associated to each other. (Table 3.2.5)

\section{DISCUSSION}

\subsection{Prevalence of DVT in adult indoor stroke population $\left(\mathrm{H}_{01}\right)$ :}

The prevalence of DVT in our study was $8.16 \%$ (95\% $\mathrm{Cl} 7.56 \%-8.64 \%)$. Matching to our study was reported by Abdel-Aziz, et al. ${ }^{9}$ from Zagazig, Egypt for the period from January 2012 to June 2012 in 280 stroke patients as $8.93 \%$ and by Bembenek, et al. ${ }^{8}$ from Warsaw city of Poland conducted from Dec. 2007 to May 2009 with 323 acute stroke patients as $8.70 \%$.

Higher frequency was reported by Karman, et al. ${ }^{12}$ as $9.24 \%$ from a sample of 249 non-hemorrhagic stroke patients from October 1988 through February 1993, by Tso SC. ${ }^{11}$ from China consisting of 35 stroke patients as $17 \%$, by Kelly, et al. ${ }^{13}$ from 102 patients with acute ischemic stroke as $18 \%$, and by CLOTS trials 1 and 2 on 5,632 stroke patients as $14.50 \% .^{10}$ No study could be retrieved from the literature which showed lower prevalence of DVT than our study.

Our observed prevalence of DVT in stroke $8.16 \%$ from a sample of 196 was similar $(p=0.7071)$ to what we expected as $8.93 \%$ from a study by Abdel-Aziz, et al. ${ }^{9}$ from a sample of 280 .

4.2 Distribution of positive cases of DVT in adult indoor stroke population across $\operatorname{sex}\left(\mathrm{H}_{02}\right)$ :

The prevalence of DVT in our study was more in women $4.59 \%(95 \% \mathrm{Cl} 3.91-5.29)$ than men 3.57\% (95\% Cl 2.93-4.26. Similarly higher prevalence in women as $6.19 \%(20 * 100 / 323=6.19 \%)$ and lower prevalence in men as $2.48 \%(8 * 100 / 323=2.48 \%)$ was shown by Bembenek, et al. ${ }^{8}$ from Warsaw city of Poland.

Our observed prevalence of DVT in adult stroke (from a sample of 196 ) in men $3.57 \%$ was statistically similar to what we expected for men $4.24 \%$ \& our observed prevalence of DVT in women $4.59 \%$ was statistically also similar to what we expected for women $3.92 \%$ from a study by Abdel-Aziz, et al. ${ }^{9}$ from Zagazig, Egypt for the period from January 2012 to June 2012 with 280 stroke patients (adjusted expected \%). (Table 3.2.2.2)

4.3 Distribution of positive cases of DVT in adult indoor stroke population across age groups $\left(\mathrm{H}_{03}\right)$ : 
The prevalence of DVT in our study was more in age group $20-60$ years $5.10 \%(95 \% \mathrm{Cl} 4.40-5.79)$ than in age group $>60$ years $3.06 \%(95 \% \mathrm{Cl} 2.46-3.74)$.

Our observed prevalence of DVT in adult stroke (from a sample of 196) in age group of 20-60 years $5.10 \% \%$ was statistically similar to what we expected for age group $\leq 65$ years $4.57 \%$ \& our observed prevalence of DVT in age group $>60$ years $3.06 \%$ was also statistically similar to what we expected for age group $>65$ years $3.59 \%$ by Abdel-Aziz, et al. ${ }^{9}$ (adjusted expected \%).

4.4 Association of presence of DVT to sex in adult indoor stroke population $\left(\mathrm{H}_{04}\right)$ :

In our study there was no association between the presence of DVT and sex $\left(\mathrm{H}_{04}\right)$ (Table 3.2.4, $\mathrm{p}=$ 0.8713 ). Similarly no association was reported by Abdel-Aziz, et al. ${ }^{9}(p=.558)$.

Contrary to our study were results by Bembenek .et al. ${ }^{8}$ from Warsaw city of Poland, who showed association between the two $(p<.05)$.

4.5 Association of presence of DVT to age groups in adult indoor stroke population $\left(\mathrm{H}_{05}\right)$ :

In our study presence of DVT and age groups was not associated to each other $\left(\mathrm{H}_{05}\right)$ (Table 3.2.5, $\mathrm{p}=0.8409$ ).

Dissimilar to our study was results by Abdel-Aziz, et al. ${ }^{9}$ from Zagazig, Egypt for the period from January 2012 to June 2012 with 280 stroke patients, reporting that presence of DVT and age groups were associated to each other in stroke patients $(p=.022)$.

\subsection{Strengths/ weaknesses of the study}

4.6.1 Marwat Logical Trajectory of Research Process: We have used this eight-step logical/ reasonable/ sensible flow of activities, including; picking out the research problems for our specified population, identifying the knowledge gaps, translating problems into categorical questions, making them as measurable objectives and accumulating expected/supposed answers for our questions from the observed answers for other similar populations (research hypotheses). Next is the substantiation of our hypotheses. It is a three steps activity, including; collection, analysis and interpretation of data. This activity will provide us observed answers for our population. If any of these observed answers is similar to its relevant expected/supposed answer, we say that the hypothesis is true and hence accepted. Otherwise, it is rejected. This way we fulfilled our objectives, got answers for our questions, filled the knowledge gaps and solved our research problems; the ultimate justification and significance of our research process. ${ }^{21-25}$

4.6.2 Population-sample-population flow: Research is an ongoing activity to identify and solve problems for a specific population. But many studies are not defining/ specifying their population of inter- est correctly and not inferring their sample results on to their specified population i.e. their studies start from the sample and end also on the sample. We have defined our population and then the sample is taken. Variables of interest are identified with their categories and data types. Data is collected by observation from that sample. Data is analyzed to describe the sample (descriptive statistics), then it is inferred to the population from which it was taken to describe that population (estimation of parameter- inferential statistics) and lastly the observed data from the sample is compared to the expected data from the population to see if this sample is similar to the population or otherwise (hypothesis testing-inferential statistics). ${ }^{21-25}$

4.6.3 Cause-n-effect analysis: The best evidence to precisely explore the determinants (causes/ risk factors) of a disease/ health related event is an experiment, which is ethically not allowed in humans. After experimental study, the cohort and then the case-control study comes to explore the determinants. The cross-sectional study gives us the least evidence, which we have used. This just tells association/ relation but not causation. It just gives evidence that the two variables are seen together more often than by chance.

\section{CONCLUSIONS \& RECOMMENDATIONS}

1. Prevalence of DVT in adult indoor stroke population of Peshawar Division, Pakistan was $8.16 \%$.

2. The prevalence was more in women than men and more in younger age group than older age group population.

3. Our overall prevalence of DVT in adult indoor stroke population was similar to expected.

4. The distribution of DVT in adult indoor stroke population across sex and age groups was similar to expected.

5. The presence of DVT was not associated to sex and age groups respectively in adult indoor stroke population of Peshawar Division, Pakistan.

Health care providers should have high index of suspicion for DVT in stroke population, try to diagnose at earlier stage and start its management as early as possible to prevent morbidity and mortality.

Acknowledgment: We are thankful to Dr. Muhammad Marwat from Gomal Medical College, D.I.Khan for granting us permission to use his "Marwat Logical Trajectory of Research Process" and to critically review our manuscript.

\section{REFERENCES}

1. Mozaffarian D, Benjamin EJ, Go AS, Arnett DK, Blaha MJ, Cushman M, et al. Executive summary: heart disease and stroke statistics-2016 update: a report from the American Heart Association. Circulation 2016 Jan 26;133 (4):447-54. 
2. Feigin VL, Krishnamurthi RV, Parmar P, Norrving B, Mensah GA, Bennett DA, et al. Update on the global burden of ischemic and hemorrhagic stroke in 1990-2013: the GBD 2013 study. Neuroepidemiol 2015 Oct 28; 45(3):161-76. https:// doi.org/10.1159/000441085

3. Boutayeb A, Derouich M, Boutayeb W, Lamlili MEN. Cerebrovascular diseases and associated risk factors in WHO Eastern Mediterranean countries. Cardiol Angiol 2014 Jan-Mar; 2(1):62-75. https://doi.org/10.9734/CA/2014/9731

4. Aminoff MJ, Kerchner GA. Nervous system disorders. In: Papadakis MA, McPhee SJ, Rabow MW, editors. Current medical diagnosis \& treatment. 55th ed. New York: McGraw-Hill; 2016. p. 978-82.

5. Wang $W$, Jiang $B$, Sun $H, R u X$, Sun $D$, Wang $\mathrm{L}$, et al; NESS-China Investigators. Prevalence, incidence, and mortality of stroke in China: results from a nationwide population-based survey of 48,0687 adults. Circulation. 2017 Feb 21; 135(8):759-71. https://doi.org/10.1161/CIRCULATIONAHA.116.025250

6. Kelly J, Rudd A, Lewis R, Hunt BJ. Venous thromboembolism after acute stroke. Stroke 2001 Jan; 32(1):262-7. https://doi.org/10.1161/01. STR.32.1.262

7. Rinde LB, Småbrekke B, Mathiesen EB, Løchen ML, Njølstad I, Hald EM et al. Ischemic stroke and risk of venous thromboembolism in the general population: the Tromsø Study. J Am Heart Assoc 2016 Nov 7; 5(11). https://doi.org/10.1161/ JAHA.116.004311

8. Abdel-Aziz A, Elfawwal MA. Incidence of deep venous thrombosis in stroke patients in medical intensive care unit Zagazig University Hospitals, Egypt. Zagazig Uni Med J 2014 Jan; 20;(1):88-96. https://doi.org/10.21608/zumj.2014.4349

9. Bembenek JP, Karlinski M, Kobayashi A, Czlonkowska A. Deep venous thrombosis in acute stroke patients. Clin Applied Thrombosis/ Hemostasis. 2012; 18(3):258-64. https://doi. org/10.1177/1076029611424575

10. Dennis M, Mordi N, Graham C, Sandercock P; CLOTS trials collaboration. The timing, extent, progression and regression of deep vein thrombosis in immobile stroke patients: observational data from the CLOTS multicenter randomized trials. J Thromb Haemost 2011 Nov; 9(11):2193-2200. https://doi.org/10.1111/j.15387836.2011.04486.x

11. Tso SC. Deep venous thrombosis after strokes in Chinese. Aust N Z J Med 1980 Oct; 10(5):5134. https://doi.org/10.1111/j.1445-5994.1980. tb04968.x

12. Kamran SI, Downey D, Ruff RL. Pneumatic sequential compression reduces the risk of deep vein thrombosis in stroke patients. Neurology 1998 Jun; 50(6):1683-8. https://doi.org/10.1212/ WNL.50.6.1683
13. Kelly J, Rudd A, Lewis RR, Coshall C, Moody A, Hunt BJ. Venous thromboembolism after acute ischemic stroke: a prospective study using magnetic resonance direct thrombus imaging. Stroke 2004 Oct; 35(10):2320-25. https://doi. org/10.1161/01.STR.0000140741.13279.4f

14. Wade S, Smith S, Claiborne Johnston, Claude Hemphill III. Cerebrovascular disease. In: Kasper DL, Hauser SL, Jameson JL, Fauci AS, Longo DL, Loscalzo J, editors. Harrison's Principles of Internal Medicine. 19th ed. New York: McGraw-Hill; 2015. p. 2559-86.

15. Raosoft $₫$ sample size calculator [internet]. Seattle, WA, USA: Raosoft Inc.; 2004. [accessed 2018 Aug 13]. Available at: http://www. raosoft. com/samplesize.html

16. Statistics Kingdom. Proportion confidence interval calculator [internet]. Statistics Kingdom; Melbourne, Australia 2007. [accessed 2018 May 27]. Available at: http://www.statskingdom. com/41_proportion_confidence_interval.html

17. Zar JH. Biostatistical Analysis. 5th ed. New York: Prentice-Hall, Inc.

18. Daniel WW. Biostatistics: A Foundation for Analysis in the Health Sciences. 7th ed. Singapore: John Wily; 2005

19. Social Science Statistics. Statistical Tests Calculators [Internet]. [accessed 2018 Oct 12]. Available from: https://www.socscistatistics.com/tests/ goodnessoffit/default2.aspx

20. Social Science Statistics. Statistical Tests Calculators [Internet]. [accessed 2018 Oct 12]. Available from: https://www.socscistatistics.com/tests/ chisquare2/default2.aspx

21. Ghori MR, Khan H, Marwat M. Distribution of non-malignant hematological disorders by sex, age groups and type of disease based on bone marrow aspiration in population of Khyber $\mathrm{Pa}$ khtunkhwa, Pakistan. Gomal J Med Sci 2019 Apr-Jun; 17 (2): 29-36. https://doi.org/10.46903/ gjms/17.02.1926

22. Butt M, Rehman MU, Khan AR, Abrar A. Frequency of triple-vessel coronary artery disease in adult type 2 diabetics versus non-diabetics in coronary artery disease population of Islamabad, Pakistan. Gomal J Med Sci 2019 Apr-Jun; 17(2):37-41. https://doi.org/10.46903/gjms/17.02.2029

23. Ain N, Khan S, Marwat M, Khan N, Ahmad I, Ramzan F, et al. Frequency, distribution and determinants of hypertension in adult stroke population of D.I.Khan Division, Pakistan. Gomal J Med Sci 2019 Jul-Sep; 17 (3):81-9. https://doi. org/10.46903/gjms/17.03.2076

24. Akhtar A, Ali SM, Naqi SA, Aziz T, Shinwari W, Shah SFH. Efficacy of acetic acid versus ciprofloxacin ear drops in achieving dry ears in chronic suppurative otitis media in adult population of Islamabad, Pakistan: a non-randomized control trial. Gomal J Med Sci 2019 Jul-Sep; 17 (3): 90-4. https://doi.org/10.46903/gjms/17.03.2007 
25. Marwat M, Ahmad I, Ashiq F, Ali S, Zamir S, Rehman MU, et al. Frequency, distribution and determinants of diabetes mellitus in adult acute coronary syndrome population of D.I.Khan Division, Pakistan. Gomal J Med Sci 2019 OctDec; 17 (4):131-43. https://doi.org/10.46903/ gjms/17.04.2106

Authors declare no conflict of interest. GRANT SUPPORT AND FINANCIAL DISCLOSURE None declared.

\section{AUTHORS' CONTRIBUTION}

The following authors have made substantial contributions to the manuscript as under:

Conception or Design:

Acquisition, Analysis or Interpretation of Data:

Manuscript Writing \& Approval:

All the authors agree to be accountable for all aspects of the work in ensuring that questions related to the accuracy or integrity of any part of the work are appropriately investigated and resolved. 